\title{
KONSEP PERENCANAAN PERUMAHAN NELAYAN DI PANTAI POHUWATO PENDEKATAN PADA ARSITEKTUR VERNACULAR
}

\author{
Nurmiah $^{1}$, \\ 1, Prodi Arsitektur, Fakultas Teknik dan Perencanaan, Universitas Pohuwato Gorontalo
}

\begin{abstract}
Abstrak
Nelayan merupakan kelompok masyarakat yang mata pencahariannya sebagian besar bersumber dari aktivitas menangkap ikan dan mengumpulkan hasil laut lainnya. Ini merupakan aktifitas keseharian, untuk tipe Nelayan dibedakan menjadi tiga kelompok, yaitu nelayan buruh, nelayan juragan dan nelayan perorangan. Pola aktifitas dan tipe ini sangat mempengaruhi akan model bangunan dan pola visual fungsi bangunan pada suatu kawasan Kehidupan permukiman nelayan selalu di indentikkan dengan kumuh salah satu faktor adalah kemiskinan merupakan suatu masalah yang bersifat multi dimensional, dalam arti berkaitan dengan aspek sosial, ekonomi,budaya, politik dan aspek lainnya. kemiskinan merupakan masalah dalam pembangunan yang ditandai dengan pengangguran dan keterbelakangan, yang kemudian meningkat menjadi ketimpangan. Sebagai suatu masyarakat yang tinggal di kawasan pesisir, masyarakat memiliki karakteristik sosial tersendiri yang berbeda dengan masyarakat yang tinggal di wilayah daratan. Di beberapa kawasan pesisir yang relatif berkembang pesat, struktur masyarakatnya bersifat heterogen, terbuka terhadap perubahan dan interaksi sosial. Hal ini menjadikan facade dan arah perencanaan kawasan yang tidak terarah antara bangunan lama dan bangunan baru yang tumbuh di kawasan ini . Sehingga dalam penelitian ini saya menganilisis untuk mendapatkan konsep perencanaan kawasan yang tepat bagi perumahan nelayan khususnya pada facade bangunan apakah pendekatan nilai nilai vernakular bisa di terapkan pada perencanaan kawasan rumah nelayan ini khususnya di rumah nelayan desa pohuwato timur.
\end{abstract}

Kata kunci: Perumahan, Nelayan, Vernacular

\begin{abstract}
Fishermen are community groups that come from fishing and collecting other marine product. This is a living day activity, for types of fishermen divided into three groups. Namely labor fisherman, skipper fisherman and individual fishermen. The pattern of activity and this type greatly affects the building model and the visual pattern of building functions in an area. the life of fishermen settlemens is always indentified with the slums one of the factors is poverty is a multi dimensional problem, in the sense relating to social, economic, cultural aspect, politics and other aspect, poverty is a problem in development characterized by unemployment and underdevelopment, wich then increases to inequality. As a community living in coastal areas, the community has its own social characteristics that are different from those who live in the mainland. In some coastal areas that are relatively rapidly developing, the structure of the community is heterogeneous, open to change and social interaction. This make the facade and direction of area planning not directed between the old buildings. So in this study I analyzed to get the right area planing concept for fishermen housing, especially on the building facade, whether the vernacular value approach can be applied to the planinng af the fishing house area. especially in fishermen house in pohuwato village east . their livelihoods are mostly new building new building they have grown in the region
\end{abstract}

Key Word: Housing, Fishermen, Vernacular

\section{PENDAHULUAN}

Nelayan merupakan kelompok masyarakat yang mata pencahariannya sebagian besar bersumber dari aktivitas menangkap ikan dan mengumpulkan hasil lautlainnya. Nelayan dibedakan menjadi tiga kelompok, yaitu nelayan buruh, nelayan juragan dan nelayan perorangan. Desa Pohuwato Timur merupakan daerah yang termasuk bagian dari wilayah Kecamatan Marisa Pesisir selatan yang memiliki daerah tepi pantai dan dihuni oleh masyarakat yang berprofesi sebagai nelayan baik itu nelayan budidaya maupun nelayan tangkap.Pada dasarnya suatu permukiman kumuh terdiri dari beberapa aspek penting, yaitu tanah atau lahan, rumah atau perumahan, komunitas, sarana dan prasarana dasar, yang terajut dalam suatu sistem sosial, sistem ekonomi dan budaya baik dalam suatu ekosistem lingkungan permukiman kumuh itu sendiri. Perumahan ini termasuk dalam wilayah desa Pohuwato Timur Kecamatan Marisa Kabupaten Pohuwato yang terletak ditepian laut, sehingga mempunyai potensi sumber daya alam perikanan laut yang sangat besar dan juga mempunyai potensi pariwisata yang cukup baik karena berada di tepi pantai. Dengan potensinya itu perumahan nelayan ini sangat dimungkinkan untuk menjadi sebuah perumahan nelayan yang mandiri dan dapat mendukung pariwisata khususnya wisata pantai Pohon Cinta. 
Tabel 1. Jumlah Penduduk Pohuwato Timur 2018

\begin{tabular}{|c|l|c|c|}
\hline NO & \multicolumn{1}{|c|}{ NAMA } & JUMLAH & KET \\
\hline \multirow{2}{*}{1} & $\bullet$ LAKI-LAKI & 1217 & \\
& $\bullet$ PEREMPUAN & 1145 & \\
& $\bullet$ ANAK-ANAK & 405 & \\
\hline \multirow{2}{*}{2} & $\bullet$ KEPALA & 611 & \\
\hline
\end{tabular}

Dengan letaknya yang sangat strategis perumahan ini bisa di akses dari banyak arah oleh masyarakat yang ingin menuju ke perumahan nelayan ini, sehingga perumahan nelayan ini mempunyai aksesibilitas yang cukup tinggi. Saat ini Pemerintah Provinsi dan Pemerintah Kabupaten sedang mengiatkan program pengembangan pariwisata, salah satunya adalah pengembang Pohuwato Timur, pembangunan yang telah dilaksanakan adalah dibukanya jalan pariwisata yang memotong diantara perumahan nelayan dengan bibir pantai serta dibangunnya fasilitas-fasilitas wisata pantai antara lain Marina beach resort, taman-taman, area parkir serta failitas penunjang lainnya.

Namun, dengan sebegitu besar potensi yang sebenarnya dimiliki oleh kampung nelayan, belum dimanfaatkan secara optimal oleh Pemerintah, maupun oleh masyarakat kampung nelayan sendiri terutama dalam mendukung keberadaan wisata Pohon Cinta. Pembangunan diperkampungan nelayan ini bisa dikatakan masih tertinggal dibanding dengan kawasan lain di Kabupaten Pohuwato, selain itu bila dilihat dari sisi sumber daya manusia, masyarakat kampung nelayan juga masih sangat rendah karna rata-rata mereka hanya lulusan sekolah dasar. Permasalahan yang lain yaitu, selain sebagai perkampungan yang berada pada kawasan wisata, kampung ini kurang didukung dengan adanya fasilitas fasilitas infrastruktur perumahan karena akibat kepadatan penduduk yang terjadi di desa ini sehingga guidlines pada perumahan ini tidak jelas, dan berdasar latar belakang dari masalah ini maka ingin diadakan penelitian tentang arahan dan pola yang tepat bagi kawasan ini dengan konsep pendekatan arsitektur vernakular.

Sehingga mendapatkan rancangan sistem pola tata massa dan sistem sirkulasi pada Perencanaan Perumahan Nelayan di Pantai Pohuwato pendekatan arsitektur vernakular yang sesuai.

\section{ISI PENELITIAN}

\section{a. Metode Penelitian}

Analisis Kebutuhan Perumahan Nelayan Di Pantai Pohuwato memakai analisis kualitaif Kebutuhan perencanaan perumahan nelayan dipantai pohuwato ini berdasarkan pada kebutuhan terhadap nelayan. nelayan sudah menjadi bagian dari kehidupan masyarakat saat ini. Maka dengan ini penekanan desain arsitektur vernakular akan menjadikan perumahan nelayan sebagai suatu tempat tinggal yang akan di banggakan. Karena sampai saat ini Pohuwato belum banyak tempat perumahan nelayan

Menurut sugiono (2008), metode analisis kuantitatif adalah pendekatan ilmiah atau penelitian (perancangan) yang memandang suatu realitas itu dapat diklasifikasikan, konkrit, teramatir dan terukur, hubungan variabelnya bersifa sebab akibat di mana data penelitiannya berupa angka-angka dan analisisnya menggunakan statistik.

Pemilihan data yang di peroleh yaitu dari :

a. Data dari Dinas Perhubungan dan Pariwisata Kabupaten Pohuwato

b. Data dari Dinas Pekerjaan Umum Kabupaten Pohuwato

c. Data dari Pemda Kabupaten Pohuwato

d. Teknik pengumpulan data yang digunakan dalam penelitian ini adalah sebagai berikut: Studi literatur, dilakukan untuk mendapatkan data-data sekunder, dalam hal ini termasuk studi kepustakaan, pengumpulan data informasi dan peta dari instansi terkait.

e. Survey lapangan, dilakukan dengan mengamati secara langsung facade bangunan dan pola kawasan obyek-obyek di lapangan sebagai studi banding.

f. Wawancara, dilakukan dengan pihak-pihak yang terkait dengan topik permasalahan untuk mendapatkan data primer

\section{b. Program Dasar Fungsional}

\section{1) Analisa Kegiatan}

Semua data yang diperoleh dari kompilasi data dianalisa untuk memperoleh pemecahan dengan mengemukakan alternatif-alternatif pemecahan.

2) Fasilitas dalam Perumahan Nelayan Di Pantai Pohuwato dengan pendekatan arsitektur vernakular

Adapun ruang-ruang yang terdapat pada Perumahan Nelayan Di Pantai Pohuwato

- Pola pertumbuhan perumahan tersebut kurang teratur dan tidak merata; Sarana aksesbilitas yang ada berupa jalan tanah selebar 6 meter sebagai jalan utama;

- Beberapa sarana dan prasarana lingkungan belum tersedia, seperti saluran air bersih, saluran pembuangan air, pengelolaan sampah, maupun saluran pematusan dan sebagainya;

- Fasilitas umum yang sudah ada hanya berupa fasilitas peribadatan (langgar), fasilitas perdagangan (warung kecil );

- Sebagian besar merupakan pendatang dengan status rumah menyewa 
Tabel 1. Karakteristik Fisik Perumahan Nelayan

\begin{tabular}{|c|c|c|}
\hline No & $\begin{array}{l}\text { Sumber } \\
\text { Pustaka }\end{array}$ & $\begin{array}{c}\text { Karakteristik Fisik Pemukiman } \\
\text { Nelayan }\end{array}$ \\
\hline 1 & $\begin{array}{c}\text { Dpu Cipta } \\
\text { Karya,2012 }\end{array}$ & 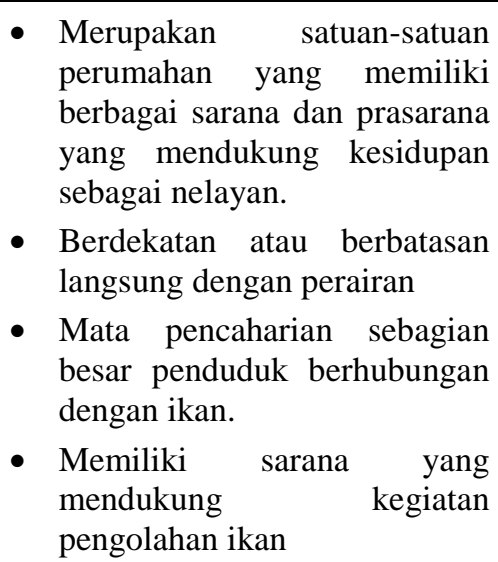 \\
\hline 2 & $\begin{array}{c}\text { Syahriarto, } \\
2013\end{array}$ & $\begin{array}{ll}\text { - } & \text { Tersusun atas satuan } \\
\text { perumahan } & \\
\text { - } & \begin{array}{l}\text { Dilengkapi sengan sarana } \\
\text { prasarana yang sesuai }\end{array} \\
\text { - } & \text { Harus memenuhi prinsip layak } \\
\text { huni }\end{array}$ \\
\hline 3 & $\begin{array}{c}\text { Umbara, } \\
2003\end{array}$ & $\begin{array}{l}\text { - } \begin{array}{l}\text { Bangunan rumah semi/non } \\
\text { permanen }\end{array} \\
\text { - Adapula rumah model } \\
\text { panggung untuk mengindari } \\
\text { banjir saat musim angin barat }\end{array}$ \\
\hline 4 & Amri, 2001 & $\begin{array}{l}\text { - Rumah dibangun berimpitan } \\
\text { di lahan yang sempit } \\
\text { - Adanya polusi udara akibat } \\
\text { limbah olahan ikan } \\
\text { - Sistem persampahan buruk }\end{array}$ \\
\hline 5 & $\begin{array}{c}\text { Ramdani } \\
\text { dan Ragil. } \\
\text { H ,2013 }\end{array}$ & 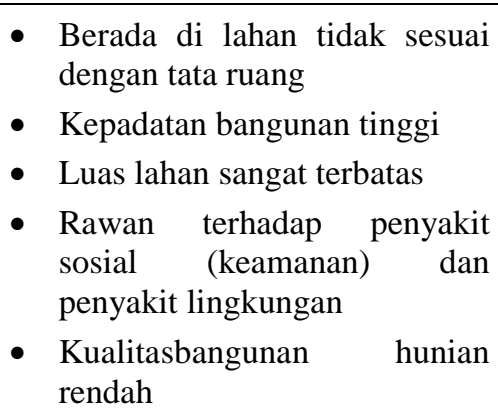 \\
\hline 6 & $\begin{array}{c}\text { Winoto; } \\
2006\end{array}$ & $\begin{array}{l}\text { - } \text { Kepadatan bangunan tinggi } \\
\text { - Kumuh (tidak teratur,kotor) } \\
\text { - } \text { Menggunakan konstruksi } \\
\text { sederhana, tradisional dan } \\
\text { konvensional yang kurang } \\
\text { memperhitungkan bahaya }\end{array}$ \\
\hline
\end{tabular}

Berdasarkan berbagai konsep di atas maka saat ini arsitektur vernakular dapat disimpulkan sebagai arsitektur yang memiliki sifat ke-lokal-an. Arsitektur vernakular adalah desain arsitektur yang menyesuaikan iklim lokal, menggunakan teknik dan material lokal, dipengaruhi aspek sosial, budaya, dan ekonomi masyarakat setempat. Berbagai macam konsep yang dapat diidentifikasikan sebagai dasar pertimbangan terbentuknya vernakular di atas memiliki pengaruh pada arsitektur vernakular yang berbeda-beda tergantung dari lokasi yang berlainan. Perbedaan lokasi ini sangat besar pengaruhnya pada arsitektur vernakular. Indonesia adalah salah satu negara yang memiliki banyak ragam arsitektur vernakular.

Masyarakat Gorontalo memiliki arsitektur lokal berbentuk panggung yang dikenal dengan nama rumah "Budel". Budel adalah istilah masyarakat lokal dalam menyebut rumah dalam hal ststusnya sebagai rumah warisan yang tidak memiliki hak kepemilikan yang jelas karena ketika pemilik utama (orang tua) meninggal dunia tidak sempat meninggalkan hak waris kepada keturunannya sehingga biasanya hanya sekedar untuk dihuni secara turun temurun oleh anak, cucu, dan keturunan-keturunan selanjutnya.

Namun tidak semua rumah Budel adalah arsitektur lokal. Masih banyak rumah-rumah bergaya kolonial peninggalan zaman Belanda di Gorontalo yang juga disebut sebagai Rumah Budel karena statusnya. Arsitektur rumah yang berbentuk panggung inilah yang menjadi saksi sejarah peradaban masyarakat Gorontalo pada zaman dahulu. Terbentuknya rumah panggung ini dipengaruhi oleh berbagai aspek seperti yang mempengaruhi terbentuknya arsitektur vernakular pada umumnya.

Tabel 2. Keterkaitan Konsep Vernakular, sikap masyarakat Gorontalo dengan pemaknaan pada Tipologi bentuk Rumah panggung Gorontalo dalam konsep kearifan lokal

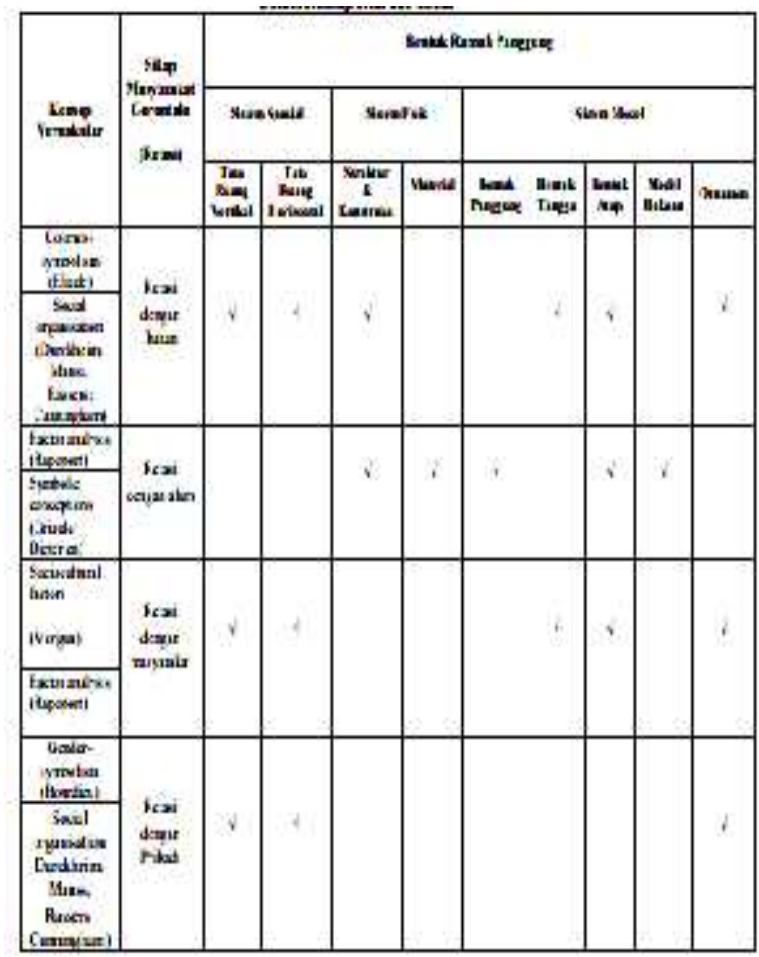


Arsitektur vernakular Gorontalo merupakan sosok lingkungan binaan yang lahir dari nilai-nilai tradisi yang kemudian berkembang melalui proses akulturasi budaya-budaya luar (Belanda, Arab, Cina, Bugis-Makassar, Sulawesi Utara) dan budaya lokal. Akulturasi budaya ini terekspresi pada sosok bentuk arsitektur vernakular Gorontalo mulai dari bentuk sampai pada penggunaan ornamen/ragam hias.

Dari analisis konsep perencanaan ini di dapatkan bahwa terjadi pergeseran pada bentuk bangunan khususnya rumah nelayan yang terdapat di Pohuwato timur. Hal ini dapat dilihat dari Proses pembangunan tidak terlepas dari tersedianya sumber daya manusia (SDM) sebagai sumber potensi daya yang di miliki oleh suatu daerah / kabupaten, karena penduduk tidak saja berperan sebagai obyek pembangunan tetapi sebagai subyek pembangunan. Berdasarkan data sensus penduduk tahun 2010, jumlah penduduk Kabupaten Pohuwato sebesar 128,748 jiwa (SP 2010) dan tingkat kepadatan penduduk sebesar 30,33 jiwa $/ \mathrm{km}^{2}$. Perkembangan jumlah penduduk di Kabupaten Pohuwato ini dapat mempengaruhi perkembangan dan pertumbuhan daerah baik fisik, ekonomi, sosial maupun politik.

Untuk jenis tanah di Kabupaten Pohuwato di dominasi oleh jenis tanah, yakni andosol, laterit, grumusol, dan podsolik yang penyebarannya berada di wilayah Kecamatan Popayato Timur, Lemito, Wanggarasi, Taluditi, Patilanggio, Randangan dan Buntulia. Sementara untuk jenis tanah regasol, litosol, organosol dan renzina dominan tersebar di wilayah Popayato Barat dan dengilo. Dimana pada jenis tanah ini cocok bangunan panggung. Untuk sarana danparasarana yang ada dapat dilihat pada table dibawah ini.

Tabel.3 Sarana dan Prasarana Pohuwato Timur

\begin{tabular}{|c|l|c|c|}
\hline No & \multicolumn{1}{|c|}{ Nama } & Jumlah & Ket \\
\hline 1 & $\begin{array}{l}\text { Luas Lahan Desa Pohuwato } \\
\text { Timur }\end{array}$ & 1,64 & \\
\hline 2 & $\begin{array}{l}\text { Prasarana Dan Sarana } \\
\text { Pendidikan } \\
\bullet \text { SMP }\end{array}$ & & \\
\hline 3 & $\begin{array}{l}\text { Prasarana Dan Sarana } \\
\text { Kebersihan }\end{array}$ & 1 & \\
\hline 4 & Jalan & 1 & \\
\hline 5 & MCK & $4 \mathrm{M}$ & \\
\hline 6 & PDAM & 400 & \\
\hline 7 & Kawasan Perdagagngan & 5 & \\
\hline
\end{tabular}

\section{HASIL \& PEMBAHASAN}

\section{a. Hasil Penelitian}

Untuk mendapatkan lokasi yang strategis untuk "Perencanaan Perumahan Nelayan di Pantai Pohuwato dengan pendekatan arsitektur vernakular", maka perlu diperhatikan hal-hal sebagai berikut:

- Mendukung arah perkembangan Kabupaten dengan melihat pola pengembangan wilayah untuk Perumahan.

- Kemudahan dalam pencapaian.

- Jaringan infrastruktur kota yang lengkap.

- Sesuai dengan Rencana Tata Ruang Wilayah (RTRW) Kabupaten Pohuwato saat ini berdasarkan Rencana Tata Ruang

Wilayah (RTRW), struktur sistem pusat kegiatan tahun 2009-2029 terbagi atas Pusat Primer dan Pusat Sekunder.

1) Faktor penunjang RTRW Kawasan Marisa, tata ruang wilayah Kabupaten Pohuwato yang strategis, iklim, morfologi serta kondisi perekonomian dan kependudukan maka beberapa factor yang menjadi penunjang pembangunan Perumahan Nelayan di Kabupaten Pohuwato adalah :

- Letak kabupaten yang berada di ujung barat provinsi Gorontalo, sehingga di perlukan modal tranportasi mudara agar dapat memaksimalakan alur perekonomian dan pendapatan kabupaten pohuwato.

- Sesuai RTRW Kabupaten Pohuwato, Perumahan Nelayan ini di bangun pada kawasan yakni di kecamatan Marisa. Dimana Kecamatan Marisa Khususnya di desa pohuwato timur ini termasuk kawasan pantai.

2) Pertumbuhan ekonomi di Kabupaten Pohuwato setiap tahun yang meningkatkan menjadi penunjang pembangunan Perumahan Nelayan

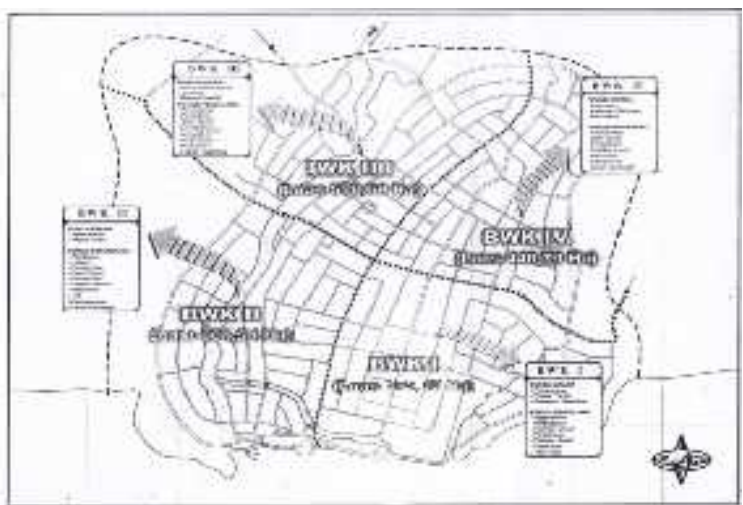

Gambar.1 Peta BWK Kabupaten Pohuwato

Bentuk bangunan sarana dan prasaran cenderung ke arah neo vernakular . padahal rumah panggung sangat cocok untuk mengatasi banjir Ciri khas yang melekat pada perumahan nelayan adalah rumah rumah non atau semi permanen, dindingnya 
terbuat dari papan atau bambu serta atapnya dari seng. Adapula rumah yang dibangun model panggung dan seluruh bahan bakunya dari kayu. Model rumah panggung ini dibuat untuk menghindari banjir saat musim angin Barat (Umbara, 2003).

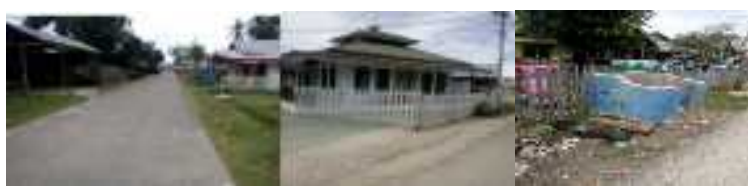

Gambar.2 Sarana dan prasarana di Pohuwato timur

Amri (2001) menyatakan bahwa karakteristik perumahan kumuh nelayan antara lain rumah rumahnya dibangun berimpitan di satu lokasi tertentu yang luasannya sangat minim di sepanjang pantai, adanya polusi udara akibat limbah hasil pengolahan ikan, dan memiliki sistem persampahan yang buruk. Menurut Ramdani dan Ragil (2013) karakteristik perumahan nelayan pada umumya berada pada lahan yang tidak sesuai dengan tata ruang, kepadatan bangunan sangat tinggi dalam luas lahan yang sangat terbatas, rawan terhadap penyakit sosial dan penyakit lingkungan serta kualitas bangunan hunian rendah. Kawasan perumahan di atas air cenderung rapat (kepadatan bangunan tinggi,dan jarak antar bangunan

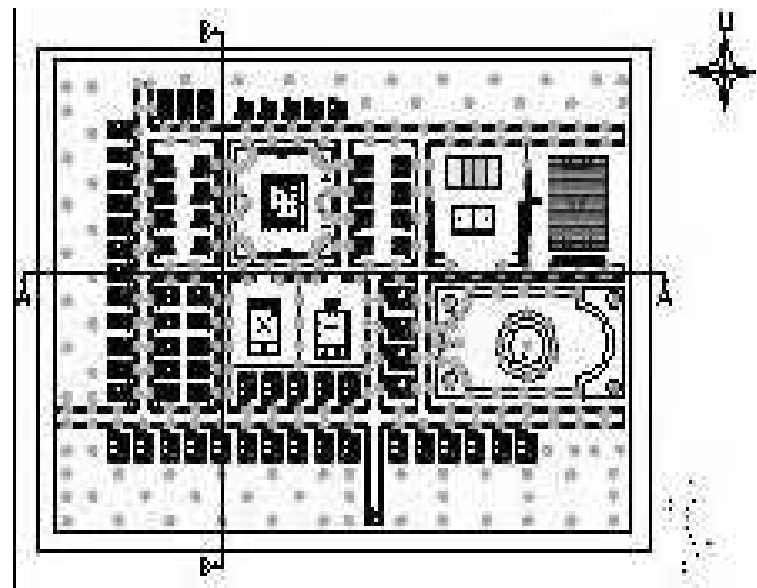

Gambar 3. Perencanaan Site Plan Kawasan.

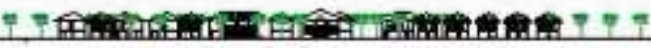

\section{จำ}

Gambar.4 Tampak kawasan Pohuwato timur
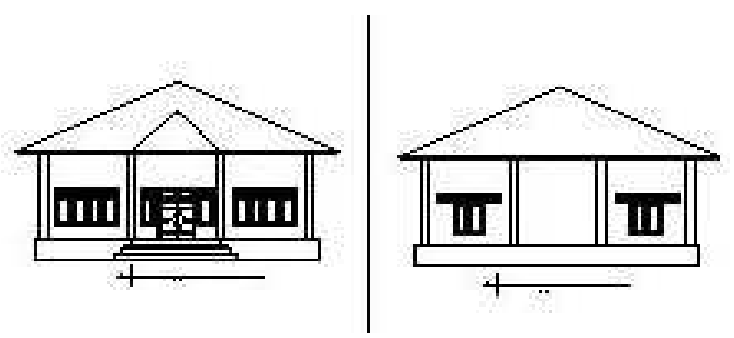

Gambar.5 Rancangan Bangunan Aula kantor desa Pohuwato Timur
Tabel 4. Hasil Penelitian kaitan karakter fisik permukiman nelayan dan Konsep Vernakular

\begin{tabular}{|c|c|c|c|c|c|c|}
\hline \multirow[t]{2}{*}{ ne } & \multirow[t]{2}{*}{ 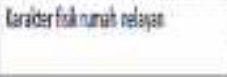 } & \multicolumn{2}{|c|}{ letd tall } & \multirow[t]{2}{*}{ leteltaguar } & \multirow[t]{2}{*}{ Noteblan } & \multirow[t]{2}{*}{ mana: } \\
\hline & & Sornquid & $\operatorname{tin}$ & & & \\
\hline 1 & 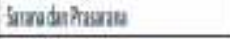 & & & Karrabidy & woda & 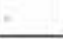 \\
\hline 2 & 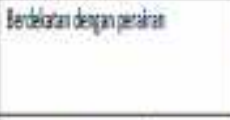 & $\begin{array}{l}\text { Lieargis } \\
\text { pritai }\end{array}$ & $\begin{array}{l}\text { Seryetar } \\
\text { treter it } \\
\text { proti }\end{array}$ & . & $\cdot$ & . \\
\hline$?$ & berra stast peorntest & laze & + & 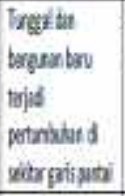 & 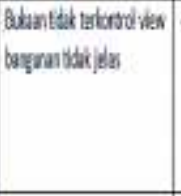 & . \\
\hline$l$ & kraiglatektinsi & is & $\begin{array}{l}\text { Poind } \\
\text { pis: }\end{array}$ & Whenituget & butanbuxix & - \\
\hline 5 & Iepodta brguentirgy & & & $\begin{array}{l}\text { Betabog̨ron } \\
\text { rinists: }\end{array}$ & 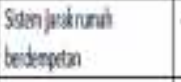 & $=$ \\
\hline 6 & Getribayra redoth & & 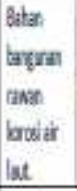 & 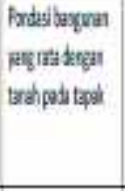 & & \\
\hline 1 & 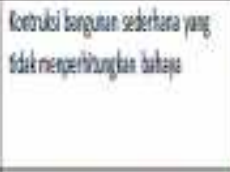 & 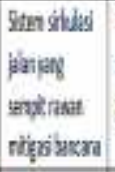 & $\begin{array}{l}\text { Deral } \\
\text { fint } \\
\text { porct }\end{array}$ & & & \\
\hline 1 & 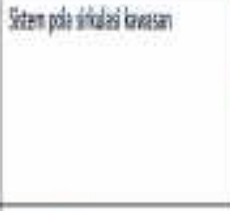 & 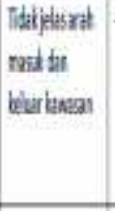 & 2 & + & - & 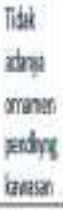 \\
\hline y & haviden & & & & 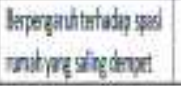 & \\
\hline
\end{tabular}

Sumber : Penulis

\section{KESIMPULAN \& SARAN}

Arsitektur vernakular Gorontalo merupakan sosok lingkungan binaan yang lahir dari nilai-nilai tradisi yang kemudian berkembang melalui proses akulturasi budaya-budaya luar (Belanda, Arab, Cina, Bugis-Makassar, Sulawesi Utara) dan budaya lokal. Akulturasi budaya ini terekspresi pada sosok bentuk arsitektur vernakular Gorontalo mulai dari bentuk sampai pada penggunaan ornamen/ragam hias.

Ada keterkaitan beberapa konsep Vernakular dengan Karakter Fisik Pemukiman nelayan pada permukiman neleyan Pohuwato Timur yang dapat di lihat pada tabel berikut :

- Untuk Penataan Permukiman Nelayan Harus di Perhatikan Karakter Fisik permukiman nelayan dengan karakter bangunan vernakular suatu daerah

- Pengaturan dan arahan Permukiman Tambahan yang menepel pada permukiman induk yang semakin menuju ke pusat air

- Penelitian selanjutnya memperhatikan konsep vernakular yang melihat keselatan permukiman khususnya pada Mitigasi Bencana. 


\section{DAFTAR PUSTAKA}

Agustina, Ina $\mathrm{H}, \quad$ Kajian tentang Konsep Keberkelanjutan pada Kota Baru Dan Perumahan Berskala Besar. 2013

Departemen Pekerjaan Umum, 2008, Penataan Ruang Wilayah, DPU, Jakarta

Direktorat Jendral Cipta Karya, 2016. Buku Penyusunan Pencegahan Perumahan dan Permukiman Nelayan.

Mulyadi 2005.Perencanaan perumahan Yogyakarta : UPPAMP YKPN Universitas Gadjah Mada

Neufert, Ernst.(1996). Data Arsitek (Jilid 1 - Edisi ke-33), Terjemahan oleh Dr.Ing. SunartoTjahjadi, 7-12.

Neufert, Ernst. (1994). Data Arsitek (Jilid 2 - Edisi ke-2), Terjemahan oleh SjamsuAmril, 14-15. 